\title{
Peningkatan Keterampilan Membaca Teks Bahasa Inggris melalui Autonomous Learning
}

\author{
Mutmainatul Mardiyah \\ Universitas Mochammad Husni Thamrin \\ mimifatchan95@gmail.com
}

\begin{abstract}
To describe how autonomous learning increases students' English text reading skills. The research was conducted at Faculty of Health, MH. Thamrin University, East Jakarta. The result of the research is as follows: (1) autonomous learning implementation at Faculty of Health, MH. Thamrin University is generally good. The achievement of all indicators of autonomous learning is very high. (2) Students' English text reading skills at Faculty of Health, MH. Thamrin University is generally very good. The achievement of all indicators of reading skills strategies is very high. (3) Autonomous learning has been successfully implemented at Faculty of Health,MH. Thamrin University to increase the students' English text reading skills. Based on the research result, the students' English text reading skills could be enhanced by deeply implementing the indicators of autonomous learning through 1). Developing self-awareness, 2). Developing effective learning strategies, 3). Developing thinking skills, 4). Developing organizational skills, 5). Developing cooperative skills, 6). Developing metacognitive skills, 7). Developing problem solving dan supporting others. It proves that autonomous learning can increase students' English text reading skills.
\end{abstract}

KEYWORDS: autonomous learning, English text, students, faculty of health

\section{PENDAHULUAN}

Penelitian ini dilatarbelakangi oleh pengalaman peneliti sebagai pengasuh matakuliah bahasa Inggris di beberapa fakultas pada perguruan tinggi. Pengalaman ini menjadi sebuah tantangan bagi peneliti untuk mendorong para mahasiswa agar mampu menerapkan pembelajaran dengan penuh kesadaran dari dalam diri mereka. Mahasiswa semester satu tentunya masih terbiasa dengan cara atau metode pembelajaran ketika mereka di bangku SMA, yaitu proses pembelajaran hanya terjadi dan terbatas pada ruang kelas dengan pengawasan atau instruksi dari para guru.

Hal ini berlanjut sampai mereka duduk di bangku kuliah pada semester-semester awal, dimana yang sering terjadi adalah para mahasiswa mengambil tempat duduk dan mendengarkan apa yang dijelaskan oleh dosen atau atas perintah dosen mahasiswa membaca apa yang dijelaskan di dalam buku teks. Selain itu, para mahasiswa sekedar mendengar dan menerima secara pasif, juga kurang ikut berpartisipasi secara aktif dalam proses pembelajaran.

Di dalam proses pembelajaran matakuliah bahasa Inggris, salah satu ketrampilan yang harus dicapai oleh mahasiswa adalah ketrampilan membaca. Bagi mahasiswa, ketrampilan membaca merupakan suatu kebutuhan yang sangat mendasar dan sangat diperlukan dalam menjalankan peran mereka sebagai mahasiswa. Peneliti sering menemukan bahwa setiap mahasiswa mempunyai ketrampilan membaca yang berbeda. Bagi mereka yang mempunya kesadaran akan pentingnya ketrampilan membaca, maka mereka akan lebih terampil dalam mengenal kata dengan cepat, terampil dalam membuat suatu kesimpulan, dan terampil dalam memperoleh ide utama dari suatu teks dibanding dengan mahasiswa yang tidak mempunyai kesadaran akan pentingnya ketrampilan membaca.

Hal yang perlu diperhatikan dalam kegiatan membaca adalah karakteristik teks. Pembaca yang baik berharap untuk memahami apa yang mereka baca. Topik teks yang dipilih harus sesuai dengan rentang usia, minat, jenis kelamin, dan latar belakang budaya siswa, untuk siapa teks-teks itu dimaksudkan . Kegiatan pra-membaca yang memperkenalkan teks harus mendorong peserta didik untuk menggunakan pengetahuan latar belakang mereka (Eskey, 1997, dikutip dalam Van Duzer, 1999). Anggota kelas dapat brainstorming ide-ide tentang makna atau arti judul atau ilustrasi dan mendiskusikan apa yang mereka ketahui. 
Hal lain yang perlu diperhatikan dalam kegiatan membaca adalah pra-membaca (pre-reading). Sebelum kegiatan membaca teks yang sesungguhnya dimulai, beberapa hal harus diperhatikan agar proses membaca dapat lebih dipahami. Hal ini diperlukan untuk memberikan informasi latar belakang yang diperlukan bagi pembaca untuk memudahkan pemahaman. Selain itu, seperti yang dinyatakan oleh Lebauer (1998), kegiatan pra-membaca dapat meringankan beban kognitif siswa saat membaca karena diskusi-diskusi sebelumnya telah dilakukan. Kegiatan diskusi ini meliputi: a) Teacher-directed pre-reading (Estes, 1999), yaitu bahwa beberapa kosakata kunci dan ide-ide dalam teks dijelaskan. Dalam pendekatan ini guru langsung menjelaskan informasi yang siswa butuhkan, termasuk konsep-konsep kunci, kosa kata yang penting, dan kerangka konseptual yang tepat. b) Interactive approach (Estes, 1999), yaitu guru memimpin diskusi di mana ia menarik informasi yang mahasiswa sudah miliki dan menyela informasi tambahan yang dianggap perlu untuk sebuah pemahaman tentang teks yang akan dibaca. Selain itu, guru dapat membuat link eksplisit antara pengetahuan dan informasi penting dalam teks. c) Purpose of reading, hal ini juga diperlukan bagi siswa untuk menyadari akan tujuan dan sasaran membaca bagian tertentu dari materi tertulis . Pada tahap awal ini dapat dilakukan oleh guru, akan tetapi sebagai pembaca yang telah mumpuni tentang tujuan ini, maka strategi peningkatan kesadaran, bisa diserahkan kepada pembaca .

Di dalam ketrampilan membaca, mahasiswa sebagai pembaca harus mampu berinteraksi dengan teks. Hal yang sering peneliti dapati di dalam kelas adalah bahwa mahasiswa belum mampu berinteraksi dengan teks yang mereka baca. Mahasiswa sekedar membaca teks tanpa mempunyai tujuan dan cara atau strategi dalam membaca teks. Mahasiswa hanya membaca apa yang dosen perintahkan untuk dibaca, tanpa mempunyai tujuan untuk apa membaca teks yang dimaksud. Oleh karenanya, pengetahuan yang dipelajari hanya terbatas pada teks yang diperintahkan oleh dosen untuk dibaca, dan para mahasiswa tidak berinisiatif untuk belajar diluar pengetahuan yang akan diberikan.

Model pengajaran dan pembelajaran yang diuraikan diatas menciptakan sikap pasif dan ketergantungan mahasiswa pada dosen dalam memperoleh pengetahuan. Oleh karenanya peneliti melakukan penelitian tindakan kelas dengan menerapkan metode Autonomous Learning, dimana dosen harus mampu menjelaskan kepada mahasiswa bahwa mereka mempunyai kapasitas untuk berpikir dan belajar secara mandiri dan beralih dari proses pembelajaran yang berpusat pada dosen menjadi proses pembelajaran dan pengajaran yang berpusat dari diri sendiri.

Malcom Knowles mengembangkan konsep Andragogy, yaitu sebuah konsep yang dikembangkan sebagai teori umum belajar dan pendidikan orang dewasa. Konsep ini membedakannya dari pedagogi yang berhubungan dengan pendidikan anak-anak. Knowles memberikan tiga (3) penjelasan tentang Autonomous Learning. Pertama, Knowles menjelaskan bahwa siswa yang mandiri adalah siswa yang lebih baik: "people who take the initiative in learning... learn more things, and learn better, than do people who sit at the feet of teachers passively waiting to be taught." (Knowles, 1975:14-15). Penjelasannya yang kedua bahwa orang dewasa tidak memerlukan guru, dalam arti bahwa mereka mampu mengambil alih pembelajaran mereka sendiri. Oleh karenanya, "self-directed learning is more in tune with our natural processes of psychological development". (Knowles, 1975:14-15). Yang ketiga Knowles menjelaskan bahwa de-institusionalisasi pendidikan, dalam bentuk sistem belajar terbuka dan independen, adalah menciptakan suatu kebutuhan pelajar untuk mengembangkan ketrampilan yang sesuai. "Students entering into these programs without having learned the skills of self-directed inquiry will experience anxiety, frustration and often failure and so will their teachers." (Knowles, 1975:14-15) Melalui penerapan autonomous learning ini, ketrampilan membaca teks bahasa Inggris pada mahasiswa jurusan Keperawatan, fakultas kesehatan di Universitas MH. Thamrin bisa meningkat.

\section{METODE}

Jenis penelitian ini adalah penelitian tindakan kelas yang berupaya untuk meningkatkan ketrampilan membaca teks bahasa Inggris melalui penerapan autonomous learning pada mahasiswa jurusan Keperawatan, Fakultas Kesehatan, Universitas Mohammad Husni Thamrin, Jakarta. Subjek penelitian adalah mahasiswa semester IV tahun akademik 2017/2018 pada jurusan Keperawatan, Fakultas Kesehatan, Universitas Mohammad Husni Thamrin berjumlah 2 kelas. Subjek penelitian ini 
dengan jumlah 30 mahasiswa. Sedangkan dosen dan pengamat dalam penelitian ini adalah dosen pengasuh matakuliah bahasa Inggris 2 yang berlatar belakang pendidikan bahasa Inggris.

Proses penelitian tindakan kelas ini melalui 4 (empat) tahapan pokok, yaitu: perencanaan, pelaksanaan, pemantauan, evaluasi dan refleksi. 1). Perencanaan, a. Rencana Tindakan pada Siklus I, dalam tahap rencana tindakan pada siklus I ini kegiatan-kegiatan yang dilakukan meliputi menyusun persiapan mengajar, menyusun tugas-tugas yang dikerjakan oleh siswa, menyediakan kertas kerja siswa; b. Rencana Tindakan pada Siklus II, yaitu rencana tindakan yang dilakukan pada tahap ini ditetapkan setelah refleksi tindakan pada siklus I dengan memperhatikan kekuatan dan kelemahan yang ditemukan. Kekuatan yang ada pada siklus I akan lebih dioptimalkan dan kelemahan yang ada akan diminimalkan. 2). Pelaksanaan kegiatan yang dilakukan pada tahap ini adalah mempersiapkan segala sesuatu yang dibutuhkan untuk melaksanakan penelitian tindakan kelas, yaitu kesiapan dosen sebagai peneliti, mahasiswa sebagai subjek penelitian, materi, dan media pembelajaran. 3). Pengamatan, kegiatan mengamati ini dilakukan oleh peneliti sendiri sebagai dosen pengampu mata kuliah bahasa Inggris, tanpa ditemani oleh teman sejawat. Hal ini dilakukan agar mahasiswa tidak merasa sedang diamati, sehingga proses penelitian ini bisa menghasilkan temuan yang sebenarnya terjadi di kelas. Jenis instrumen yang digunakan adalah format/lembar observasi yang memuat: a) interaktif dosen-mahasiswa, mahasiswa-dosen, dan mahasiswa-mahasiswa; b). aktivitas mahasiswa selama pembelajaran; c). aktivitas dosen selama pembelajaran; d). catatan lapangan. 4). Evaluasi dan Refleksi, pada kegiatan ini, data yang diperoleh pada siklus I dijadikan sebagai bahan pertimbangan untuk melakukan tindakan pada siklus II. Sedangkan evaluasi pada siklus II dijadikan sebagai bahan untuk penyusunan laporan penelitian tindakan kelas ini.

Sumber data dari penelitian ini adalah seluruh mahasiswa kelas A semester IV (empat), jurusan Keperawatan, Fakultas Kesehatan, Universitas Mohammad Husni Thamrin, Jakarta berjumlah 26 orang dengan latar belakang kemampuan berbahasa Inggris yang beragam. Instrumen yang digunakan untuk mengumpulkan data dalam penelitian ini adalah: Lembaran Observasi, dan tes yang dilakukan selama 2x, yaitu pre-test dan post test.

HASIL \& PEMBAHASAN

Untuk mengukur ketrampilan membaca teks bahasa Inggris mahasiswa digunakan rumus :

$$
\mathrm{PR}=\stackrel{\substack{\text { Skor rata-rata } \\ \text { Skor maksimum }}}{\text { X }} 100
$$

Pencapaian responden dikategorikan/dikelompokkan seperti tabel berikut:

Tabel 1. Kelas Ketercapaian

\begin{tabular}{|c|c|c|}
\hline No. & \% Ketercapaian & Kategori \\
\hline & & \\
1 & $90-100$ & Sangat baik \\
2 & $80-89$ & Baik \\
3 & $65-79$ & Cukup \\
4 & $55-64$ & Kurang \\
5 & $0-54$ & Tidak baik atau gagal \\
& & \\
& & \\
\hline
\end{tabular}

Deskripsi data penelitian disajikan untuk memberikan informasi umum tentang data yang dicari dan diperoleh melalui pretest test, post test, student journals, dan observasi kelas. Penelitian ini menjabarkan 2 (dua) variabel, yaitu autonomous learning atau pembelajaran autonomi dan ketrampilan membaca pada mahasiswa jurusan Keperawatan, Fakultas Kesehatan, Universitas Mohammad Husni Thamrin, Jakarta. 


\section{Data Ketrampilan Membaca}

Data ketrampilan membaca diperoleh melalui pelaksanaan pre-test and post-test. Kedua test tersebut mencakup elemen-elemen yang ada pada strategi membaca, yaitu: 1) Previewing; 2) Contextualizing; 3) Questioning to understand and remember; 4) Reflecting on challenges to your beliefs and values; 5) Outlining and summarizing; 6) Evaluating an argument.

\section{Pre-test Ketrampilan Membaca}

Pre-test ketrampilan membaca diberikan pada hari Rabu, tanggal 7 Maret tahun 2018. Mahasiswa yang mengikuti pre-test ini sebanyak 30 orang. Nilai minimum atau nilai terendah yang diperoleh mahasiswa pada pre-test ini adalah 48. Terdapat 2 (dua) mahasiswa yang memperoleh nilai minimum ini. Nilai 48 merupakan nilai yang tidak baik atau gagal karena nilai tersebut berada pada rentang nilai 0-54. Sedangkan nilai maksimum atau nilai tertinggi yang diperoleh mahasiswa pada pre-test ini adalah 94. Terdapat 1 (satu) mahasiswa yang memperoleh nilai maksimum ini. Nilai 94 merupakan nilai yang sangat baik karena nilai tersebut berada pada rentang nilai 90-100. Nilai rata-rata yang diperoleh mahasiswa pada pre-test ini adalah 72,03. Nilai 72,03 merupakan nilai yang cukup karena berada pada rentang nilai 65-79.

\section{Post-test Ketrampilan Membaca}

Post-test ketrampilan membaca diberikan pada hari Rabu, tanggal 23 Mei tahun 2018. Mahasiswa yang mengikuti post-test ini sebanyak 30 orang. Nilai minimum atau nilai terendah yang diperoleh mahasiswa pada post-test ini adalah 63. Terdapat 1 (satu) mahasiswa yang memperoleh nilai minimum ini. Nilai 63 merupakan nilai yang kurang karena berada pada rentang nilai 55-64. Sedangkan nilai maksimum atau nilai tertinggi yang diperoleh mahasiswa pada post-test ini adalah 98 . Terdapat 1 (satu) mahasiswa yang memperoleh nilai maksimum ini. Nilai 98 merupakan nilai yang sangat baik karena berada pada rentang nilai 90-100. Nilai rata-rata yang diperoleh mahasiswa pada post-test ini adalah 83,3. Nilai 83,3 merupakan nilai yang baik karena nilai tersebut berada pada rentang nilai 80-89. Untuk lebih jelasnya, ketiga jenis nilai tersebut bisa dilihat pada tabel berikut:

Table 2. Skor Ketrampilan Membaca

\begin{tabular}{|c|c|c|c|c|c|c|}
\hline No. & Jenis Tes & $\begin{array}{c}\text { Skor } \\
\text { Minimum }\end{array}$ & $\begin{array}{c}\text { Skor } \\
\text { Maximum }\end{array}$ & $\begin{array}{c}\text { Skor } \\
\text { Rata-rata }\end{array}$ & $\begin{array}{c}\text { Skor } \\
\text { Total }\end{array}$ \\
\hline 1. & & Pre-test & 48 & 94 & 72,03 & 2161 \\
\hline 2. & & Post-test & 63 & 98 & 83,3 & 2499 \\
\hline
\end{tabular}

Rincian tabel 2 di atas bisa dilihat pada tabel 3 berikut ini:

Tabel 3. Rincian Nilai Pre-Test dan Nilai Post-Test

\begin{tabular}{|c|c|c|c|c|c|c|c|}
\hline NO. & $\begin{array}{l}\text { Nama } \\
\text { Mahasiswa }\end{array}$ & $\begin{array}{l}\text { NILAI } \\
\text { TEST }\end{array}$ & & & \multicolumn{3}{|c|}{ NILAI POST-TEST } \\
\hline 1 & S H & 54 & 54 & 54 & 63 & 63 & 63 \\
\hline 2 & L I W & 86 & 86 & 86 & 83 & 83 & 83 \\
\hline 3 & R H S & 82 & 82 & 82 & 76 & 76 & 76 \\
\hline 4 & B K S & 82 & 82 & 82 & 86 & 86 & 86 \\
\hline 5 & S A & 53 & 53 & 53 & 87 & 87 & 87 \\
\hline 6 & M J & 79 & 79 & 79 & 86 & 86 & 86 \\
\hline
\end{tabular}




\begin{tabular}{|c|c|c|c|c|c|c|c|}
\hline 7 & C K & 90 & 90 & 90 & 97 & 97 & 97 \\
\hline 8 & A F R & 68 & 68 & 68 & 76 & 76 & 76 \\
\hline 9 & D S & 72 & 72 & 72 & 80 & 80 & 80 \\
\hline 10 & S Y & 73 & 73 & 73 & 81 & 81 & 81 \\
\hline 11 & N F J & 73 & 73 & 73 & 80 & 80 & 80 \\
\hline 12 & N P S & 72 & 72 & 72 & 81 & 81 & 81 \\
\hline 13 & P M S & 72 & 72 & 72 & 80 & 80 & 80 \\
\hline 14 & O B P & 79 & 79 & 79 & 86 & 86 & 86 \\
\hline 15 & N D A & 51 & 51 & 51 & 82 & 82 & 82 \\
\hline 16 & A Y M & 48 & 48 & 48 & 74 & 74 & 74 \\
\hline 17 & S A & 68 & 68 & 68 & 84 & 84 & 84 \\
\hline 18 & Y Y & 80 & 80 & 80 & 89 & 89 & 89 \\
\hline 19 & E N H & 62 & 62 & 62 & 83 & 83 & 83 \\
\hline 20 & R S W & 48 & 48 & 48 & 68 & 68 & 68 \\
\hline 21 & S F A & 92 & 92 & 92 & 96 & 96 & 96 \\
\hline 22 & K S & 86 & 86 & 86 & 82 & 82 & 82 \\
\hline 23 & M D & 80 & 80 & 80 & 91 & 91 & 91 \\
\hline 24 & P S & 52 & 52 & 52 & 81 & 81 & 81 \\
\hline 25 & $\mathrm{CW} \mathrm{S}$ & 76 & 76 & 76 & 83 & 83 & 83 \\
\hline 26 & $\mathrm{~N} \mathrm{H}$ & 62 & 62 & 62 & 87 & 87 & 87 \\
\hline 27 & OF M S & 94 & 94 & 94 & 98 & 98 & 98 \\
\hline 28 & A V S & 85 & 85 & 85 & 88 & 88 & 88 \\
\hline 29 & K B P & 64 & 64 & 64 & 81 & 81 & 81 \\
\hline \multirow[t]{3}{*}{30} & T B L & 78 & 78 & 78 & 90 & 90 & 90 \\
\hline & & \multirow[t]{2}{*}{48} & \multirow[t]{2}{*}{94} & \multirow{2}{*}{$\begin{array}{l}72,033333 \\
\text { average }\end{array}$} & \multirow[b]{2}{*}{$\min$} & \multirow[b]{2}{*}{$\max$} & \multirow[b]{2}{*}{ average } \\
\hline & NILAI & & & & & & \\
\hline
\end{tabular}

Dari data yang terdapat pada tabel 2 dan 3, bisa dilihat bahwa terjadi peningkatan nilai pada ketrampilan reading mahasiswa jurusan Keperawatan, Fakultas Kesehatan, Universitas Mohammad 
Husni Thamrin, Jakarta. Skor nilai minimun pada pre-test yang diraih mahasiswa adalah 48 . Sedangkan skor nilai minimum pada post-test adalah 63. Peningkatan dari nilai 48 menjadi 63 merupakan perubahan yang cukup significant, yaitu 15 poin.

Berdasar pada tabel 2 dan 3, pada post-test juga terjadi peningkatan nilai pada ketrampilan reading mahasiswa jurusan Keperawatan, Fakultas Kesehatan, Universitas Mohammad Husni Thamrin, Jakarta. Skor nilai maksimum pada post-test yang diraih mahasiswa adalah 94. Sedangkan skor nilai maksimum pada post-test adalah 98. Peningkatan dari nilai 94 menjadi 98 merupakan perubahan yang tidak cukup significant, yaitu hanya 4 poin.

Pada data yang terdapat pada tabel 2 dan 3 juga bisa terlihat bahwa terjadi peningkatan nilai pada skor nilai rata-rata ketrampilan reading mahasiswa jurusan Keperawatan, Fakultas Kesehatan, Universitas Mohammad Husni Thamrin, Jakarta. Skor nilai rata-rata pada pre-test yang diraih mahasiswa adalah 72,03. Sedangkan skor nilai rata-rata pada post-test adalah 83. Peningkatan dari skor nilai rata-rata dari 72,03 menjadi 83 merupakan perubahan yang cukup significant, yaitu 10,97 poin.

\section{Data Autonomous Learning}

Data autonomous learning diperoleh melalui pelaksanaan proses belajar setelah pelaksanaan pre-test. Penerapan proses autonomous learning tersebut mencakup 7 (tujuh) indikator sebagai berikut: 1). Developing self-awareness, 2). Developing effective learning strategies, 3). Developing thinking skills, 4). Developing organizational skills, 5). Developing cooperative skills, 6). Developing metacognitive skills, 7). Developing problem solving dan supporting others.

Indikator-indikator tersebut di atas bisa dilihat pada tabel 4 berikut ini:

Tabel 4. Data Indikator Autonomous Learning

\begin{tabular}{|c|c|}
\hline INDIKATOR & SKOR \\
\hline Self-Awareness & 528 \\
\hline Effective learning Strategies & 265 \\
\hline Thinking Skills & 357 \\
\hline Organizational Skills & 254 \\
\hline Cooperative skills & 361 \\
\hline Metacognitive Skills & 505 \\
\hline Problem Solving and Supporting others & 230 \\
\hline
\end{tabular}

Dari tabel 4 (empat) tentang indikator autonomous learning terbaca bahwa indikator self -awareness atau kesadaran diri menempati posisi tertinggi, yaitu pada angka 528 . Ini artinya bahwa sebagian besar mahasiswa jurusan Keperawatan, Fakultas Kesehatan, Universitas MH. Thamrin, Jakarta memiliki kesadaran diri yang tinggi di dalam proses belajar. Indikator self-awareness diterapkan pada mahasiswa melalui pengamatan dosen dengan menerapkan beberapa sub-indikator, yaitu : take initiative, open minded, self-motivated, organized, dan take risks.

Indikator metacoqnitive skills atau ketrampilan metakognitif mencapai angka 505. Indikator metacognitive skills atau ketrampilan metakognitif diterapkan pada mahasiswa melalui pengamatan dosen dengan menerapkan beberapa sub-indikator, yaitu kemampuan mahasiswa dalam : adapt learning style, evaluation, resources, organization and planning, dan decision making.

Indikator cooperative skills atau ketrampilan bekerjasama mencapai angka 361. Indikator cooperative skills atau ketrampilan bekerjasama diterapkan pada mahasiswa melalui pengamatan dosen dengan menerapkan beberapa sub-indikator, yaitu supportive, co-operation and collaboration.

Indikator thinking skills atau ketrampilan berpikir mencapai angka 357. Indikator thinking skills atau ketrampilan berpikir diterapkan pada mahasiswa melalui pengamatan dosen dengan menerapkan beberapa sub-indikator, yaitu enthusiastic, positive orientation, dan balanced and broad interestts. 
Indikator Effective Learning Strategies atau strategi belajar effektif mencapai angka 265. Indikator effective learning strategies atau strategi belajar effektif diterapkan pada mahasiswa melalui pengamatan dosen dengan menerapkan beberapa sub-indikator, yaitu purposeful, questioning.

Indikator Organizational Skills atau ketrampilan berorganisasi mencapai angka 254. Indikator Organizational Skills atau ketrampilan berorganisasi diterapkan pada mahasiswa melalui pengamatan dosen dengan menerapkan beberapa sub-indikator, yaitu tolerant, independent and interindependent. Indikator Problem Solving and Supporting others atau memecahkan masalah dan membantu yang lain mencapai angka 230. Indikator Indikator Problem Solving and Supporting others Organizational Skills atau memecahkan masalah dan membantu yang lain diterapkan pada mahasiswa melalui pengamatan dosen dengan menerapkan beberapa sub-indikator, yaitu problem solving dan active learning. Indikator ini adalah yang paling rendah skornya, yaitu 230. Ini artinya bahwa kemampuan mahasiswa untuk mengatasi suatu masalah dalam belajar dan pembelajaran aktif masih kurang.

\section{KESIMPULAN DAN REKOMENDASI}

Berdasarkan pada hasil dan pembahasan penelitian yang dijelaskan pada bagian sebelumnya, maka diperoleh kesimpulan bahwa: (1) Penerapan metode autonomous learning dalam proses belajar matakuliah bahasa Inggris pada ketrampilan membaca di kelas A mahasiswa semester IV tahun akademik 2017/2018, jurusan Keperawatan, Fakultas Kesehatan, Universitas MH. Thamrin, bisa meningkatkan ketrampilan membaca teks bahasa Inggris, yang meliputi: previewing, contextualizing, questinoning to understand and remember, reflecting on challenges to readers' beliefs and values, outlining and summarizing, evaluating an argument, comparing and constructing related reading. (2). Melalui penerapan indikator-indikator autonomous learning yang meliputi: developing selfawareness, effective learning strategies, organisational skills, cooperative skills, metacognitive skills, dan problems solving and supporting others, ditemukan bahwa mahasiswa semester IV tahun akademik 2017/2018, jurusan Keperawatan, Fakultas Kesehatan, Universitas MH. Thamrin, menunjukan kemajuan dalam pengembangan dari semua indikator ini pada mereka, sehingga ketrampilan membaca teks bahasa Inggris mereka menunjukkan peningkatan.

Mengacu pada hasil temuan dan kesimpulan tersebut di atas, ada beberapa saran dan masukan yang perlu penulis sampaikan, yaitu: 1). Kepada mahasiswa, agar selalu membiasakan dan berlatih dengan tekun untuk menerapkan secara bertahap atau secara keseluruhan semua indikator dari autonomous learning, sehingga mereka bisa dengan mudah untuk meningkatkan ketrampilan membaca teks, khususnya membaca teks bahasa Inggris; 2). Kepada para dosen, agar bisa mempertimbangkan untuk juga menerapkan autonomous learning kepada mahasiswa, agar capaian pembelajaran, yang diharapkan pada anak didiknya, khususnya matakuliah bahasa Inggris pada ketrampilan membaca teks bisa meningkat. 


\section{DAFTAR PUSTAKA}

Aguirre, J., \& Ramos, B. (2009). Guidance in reading strategies: A first step towards autonomy learning in a semi-distance education program. PROFILE Issues in Teachers' Professional Development, 11(1), 41-56.

Alderson, J. C. (2000). Assessing reading. Cambridge, UK: Cambridge University Press.

Burns, A. (2010). Doing action research in English language teaching: A guide for practitioners. New York, NY: Routledge.

Cantrell, S. C., \& Carter, J. C. (2009). Relationships among learner characteristics and adolescents' perceptions about reading strategy use. Reading Psychology, 30(3), 195-224.

Carrell, P. L. (1989). Metacognitive awareness and second language reading. The Modern Language Journal, 73(2), 121-134.

Cohen, L., Manion, I., \& Morrison, K. (2007). Research methods in education (6th ed.). London, UK: Routledge Falmer.

Dickinson, L. (1995). Autonomy and motivation: A literature review. System, 23(2), 165-174.

Guilloteaux, M. J., \& Dörnyei, Z. (2008). Motivating language learners: A classroom-oriented investigation of the effects of motivational strategies on student motivation. TESOL Quarterly, 42(1), $55-77$.

Guthrie, J., Wigfield, A., Metsala, J. L., \& Cox, K. E. (1999). Motivational and cognitive predictors of text comprehension and reading amount. Scientific Studies of Reading, 3(3), 231-256.

Hedge, T. (2003). Teaching and learning in the language classroom. New York, NY: Oxford University Press.

Holec, H. (1981). Autonomy and foreign language learning. Oxford, UK: Pergamon.

Jiménez, P. (2000). Teaching reading strategies. Bogotá, CO: Universidad Externado de Colombia. Little, D. (1991). Learner autonomy: Definitions, issues, and problems. Dublin, IE: Authentik.

Nunan, D. (1999). Second language teaching and learning. Boston; MA: Heinle Cengage Learning.

Nuttall, C. (1982). Teaching reading skills in a foreign language. London, UK: Heinemann.

Nuttall, C. (1996). Teaching reading skills in a foreign language (2nd ed.). Oxford, UK: Heinemann.

Ríos, S. R., \& Valcárcel, A. M. (2005) Reading: A meaningful way to promote learning English in high school. PROFILE Issues in Teachers' Professional Development, 6(1), 59-72.

Stern, P. N., \& Porr, C. (2010). Essentials of accessible grounded theory. Walnut Creek, CA: Left Coast Press.

Wallace, M. J. (2002). Action research for language teachers. Cambridge, UK: Cambridge University Press. 